\title{
Inventory classification tree model based on inventory Classification policy in Manufacturing Enterprises
}

\author{
Dongjuan Xue \\ School of Mechanical and Power Engineering, Dalian Ocean University, Liaoning, China \\ xuedongjuan@163.com
}

Keywords: classification tree model, inventory classification, Fuzzy Neural Network

Abstract. Material inventory management plays an increasingly important role in modern operations management within manufacturing enterprises. And a multi-attribute classification model has been put up based on the application of the decide tree model and fuzzy artificial neural network. First the material inventory styles are classified. Then a decision tree model is defined based on inventory classification result. The value of the node is decided by Fuzzy Neural Network if multi-attribute decision is needed and material inventory strategy can be decided with the classification tree and inventory strategy table. In the end, the implementation of the model in a manufacturing enterprise resource plan system is presented.

\section{Introduction}

The correct inventory strategy is important to control reasonable inventory within assembly workshops $^{[1]}$. By working out the correct inventory strategy to control reasonable inventory, not only the equipment in operating condition is to keep, but also the inventory keeping cost are as low as possible. Connecting the characteristics of materials supply and the relationship between parts and production, a classification model based on materials attributes is put forward. Using this model a spare part could be vested in corresponding inventory category and according to this category to make out the stock and inventory policy for this part.

\section{Components and parts classification}

Decision tree model of components and parts classification. This paper developed a multi-attribute classification model based on the application of two different methods ${ }^{[2,3]}$ : the decide tree model and fuzzy artificial neural network (FANN).the classification results are the policy of spare parts inventory management and shortage cost, usage rate, inventory cost, purchasing cost, the ability of demand forecasting and parts supply characters are the factors considered in this model.

The decision problem at each node of the diagram is supported by using FANN model and according to the answer to the nodes, the decide tree guides the user towards the best classification for each type of spare parts. In this paper, a particular decision tree model developed in a company operating in a manufacturing enterprise is presented, as shown in Fig.1.

Parts usage rate. Parts usage rate means the probability of the parts to be used. The higher the parts usage rate is, the higher the usage probability is .The items to that factor are listed in table 1.

Carrying ,Holding,or Possession Costs. These include handling charges; the cost of storage facilities or warehouse rentals; the cost of equipment to handle inventory; storage, labor, and operating costs, insurance premiums; breakage; pilferage; obsolescence; and investment or opportunity costs. In short, any cost associated with having, as opposed to not having, inventory is included. And the items are list in table 2.

Ordering or Purchase Costs. These include the managerial, clerical, material, telephone, mailing, fax, accounting, transportation, inspection, demand forecasting, and receiving costs with a purchase or production order Items considered are listed in table 3. 


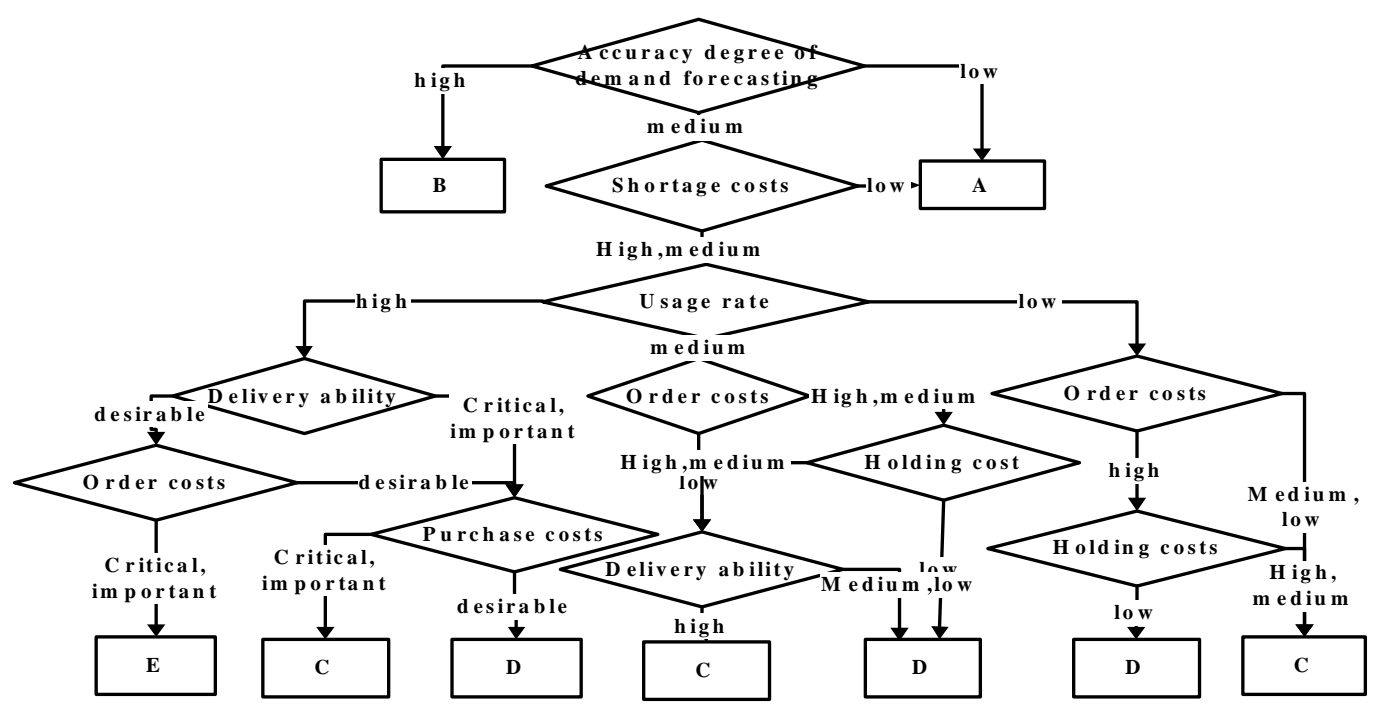

Fig.1. Decision tree of components and parts

Table 1.Items to parts usage rate

\begin{tabular}{|c|l|l|}
\hline \multirow{3}{*}{ Item } & Grade & Criteria \\
\hline \multirow{3}{*}{ Number } & High & More than 10 \\
\cline { 2 - 3 } & Medium & Between 2 and 10 \\
\cline { 2 - 3 } & Low & Only one \\
\hline \multirow{3}{*}{ Redundancies } & High & No redundancy \\
\cline { 2 - 3 } & Medium & Simple redundancy \\
\cline { 2 - 3 } & Low & Multiple redundancy \\
\hline
\end{tabular}

Table2. Items to parts holding cost

\begin{tabular}{|l|l|l|}
\hline \multicolumn{1}{|c|}{ Item } & Grade & Criteria \\
\hline \multirow{3}{*}{ Space required } & High & More than 3 standard locations per unit \\
\cline { 2 - 3 } & Medium & Up to 2-3 standard locations per unit \\
\cline { 2 - 3 } & Low & No more than 1 standard location per unit \\
\hline \multirow{2}{*}{$\begin{array}{l}\text { Inventory service } \\
\text { cost }\end{array}$} & High & More than 30\% unit-price \\
\cline { 2 - 3 } & Medium & Between 30\% and 5\% unit-price \\
\cline { 2 - 3 } Inventory risk cost & Low & Less than 5\% unit-price \\
\hline \multirow{3}{*}{} & High & Obsolesce or deteriorate easily \\
\cline { 2 - 3 } & Medium & Obsolesce or deteriorate a little \\
\cline { 2 - 3 } & Low & No obsolescence or deterioration \\
\hline
\end{tabular}

Table3. Items to parts purchase costs

\begin{tabular}{|l|l|l|}
\hline item & grade & criteria \\
\hline \multirow{3}{*}{ Order cost } & High & More than $15 \%$ unit-price \\
\cline { 2 - 3 } & Medium & Between $10 \%$ and $15 \%$ unit-price \\
\cline { 2 - 3 } & Low & No more than $10 \%$ unit-price \\
\hline \multirow{2}{*}{$\begin{array}{l}\text { Transportation } \\
\text { costs }\end{array}$} & High & More than $25 \%$ unit-price \\
\cline { 2 - 3 } & Medium & Between $18 \%$ and $25 \%$ unit-price \\
\cline { 2 - 3 } & Low & No more than $18 \%$ unit-price \\
\hline \multirow{3}{*}{ Testing cost } & High & More than $8 \%$ unit-price \\
\cline { 2 - 3 } & Medium & Between $3 \%$ and $8 \%$ unit-price \\
\cline { 2 - 3 } & Low & No more than $3 \%$ unit-price \\
\hline
\end{tabular}

Shortage cost. The costs of being out of a part generally include quality as well as lost production, and these costs are difficult to quantify. Increased risk to personnel may also be a factor, and costs associated with such risks are not easy to calculate, as shown in Table 4. 
Table 4 Items of parts shortage cost

\begin{tabular}{|c|l|l|}
\hline \multicolumn{1}{|c|}{ Item } & \multicolumn{1}{|c|}{ Grade } & Criteria \\
\hline \multirow{2}{*}{$\begin{array}{l}\text { Quality problem and } \\
\text { production loss }\end{array}$} & High & Production lost or quality deteriorated heavily \\
\cline { 2 - 3 } & Medium & Production lost or quality deteriorated but not seriously \\
\cline { 2 - 3 } Staff safety & Low & No effect \\
\cline { 2 - 3 } & High & One or more fatality \\
\cline { 2 - 3 } & Low & One or more seriously injured \\
\hline \multirow{4}{*}{ Domino effect } & High & Global productive effect(many productive parts are involved) \\
\cline { 2 - 3 } & Medium & $\begin{array}{l}\text { Limited productive effect(limited productive parts are } \\
\text { involved) }\end{array}$ \\
\cline { 2 - 3 } & Low & No domino effect \\
\hline
\end{tabular}

Delivery ability. Delivery ability in the simplest sense refers to the ability of the supplier to provide spare parts in conformance with specifications and meet delivery dates without expediting. The attributes to that factor list in table 5.

Table 5. Delivery ability

\begin{tabular}{|c|l|l|}
\hline Item & \multicolumn{1}{|c|}{ grade } & \multicolumn{1}{c|}{ criteria } \\
\hline \multirow{4}{*}{ Time } & High & $\begin{array}{l}\text { Meets delivery dates without expediting or requested delivery } \\
\text { dates are usually accepted. }\end{array}$ \\
\cline { 2 - 3 } & Medium & $\begin{array}{l}\text { Usually meets shipping dates without substantial follow-up } \\
\text { (sometimes late). }\end{array}$ \\
\cline { 2 - 3 } & Low & $\begin{array}{l}\text { Shipments usually late, delivery promises seldom met, constant } \\
\text { expediting required. }\end{array}$ \\
\hline \multirow{3}{*}{ Quantity } & High & All correct quantities (within tolerance). \\
\cline { 2 - 3 } & Medium & Up to 5\% shipments incorrect ( within tolerance ) . \\
\cline { 2 - 3 } & Low & $>5 \%$ of shipments outside tolerance. \\
\hline
\end{tabular}

\section{Grade decision of the tree node}

When the parts classification is considered, the choice at each node of the diagram is probably complex and difficult .To support the selection process of the analyst, FANN is used to change the multi-attribute decision problem into multi-attribute classification problem. The classification result is the answer of the node choice ${ }^{[4,5]}$. In this way, numerous attributes influencing the parts supply are taken into account in an easy manner.

The factors of the node problem are the input of the FANN, taking spare parts Purchase Costs as an example, the input is $\mathrm{X}=\{$ Order cost, Transportation costs, Testing cost $\}$, the vector is $\left(\mathrm{x}^{1}, \mathrm{x}^{2}, \mathrm{x}^{3}\right)^{T}$ ; Output is $\mathrm{Y}=\{$ high, medium, low $\}$, the vector is $\left(\mathrm{y}^{1}, \mathrm{y}^{2}, \mathrm{y}^{3}\right)^{T}$.

The first tier is input tier, each input vector $\mathrm{X}=\left(\mathrm{x}^{1}, \mathrm{x}^{2}, \mathrm{x}^{3}\right)^{T}$ means factors which related to node question, $\mathrm{x}^{i}$ means the ith factor of that question.

Every node at the second tier means the membership of evaluation set relative to the input vector, the evaluation set of every factor $C^{i}=\{$ critical, important, desirable $\}$, vector of membership is $\mu^{i}$ $\left(\mathrm{x}^{i}\right)=\left(\mu^{i 1}, \mu^{i 2}, \mu^{i 3}\right)^{T}, \mu^{i k} \square[0,1], \mathrm{i}=1,2,3 ; \mathrm{k}=1,2,3$.

Every node at the third tier means a fuzzy rule, every rule application degree is

$\alpha j=\operatorname{Min}\left\{\mu 1^{i 1}, \mu 2^{i 2}, \mu 3^{i 3},\right\}, i 1, i 2, i 3=1,2,3, \ldots, n ; j=1,2 \ldots 3^{3}$;

FANN structure is shown in Fig. 2:

Normalization calculate will be finished at the fourth tier, that is 


$$
\bar{\alpha}_{j}=\frac{\alpha_{j}}{\sum_{i=1}^{N 4} \alpha_{i}}, \mathrm{~N} 4=3^{3}
$$

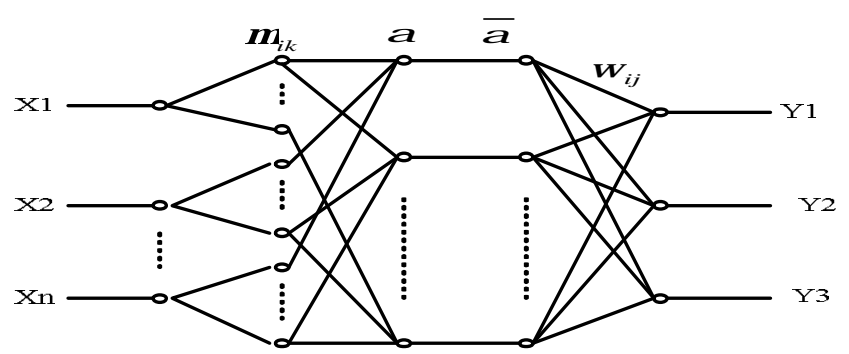

Fig. 2. FANN structure for purchase costs

The fifth tier of the FANN is the output tier, N5 (the node number) is 3.

$$
y^{i}=\sum_{j=1}^{N 4} \omega_{i j} \bar{\alpha} i=1,2,3
$$

The answer of the node choice is the category which corresponds to the max value of $\mathrm{y}^{i}$.

\section{Decision support for parts inventory based on inventory Category policy}

This paper develops a decision processing (Fig.3) and parts inventory tactic table to support parts inventory management. Because of parts inventory tactic relating to many factors, the tactic for parts is not changeless. If some factors or criteria are changed, the support tool should be run to get a new tactic for the parts in order to avoid unnecessary loss.

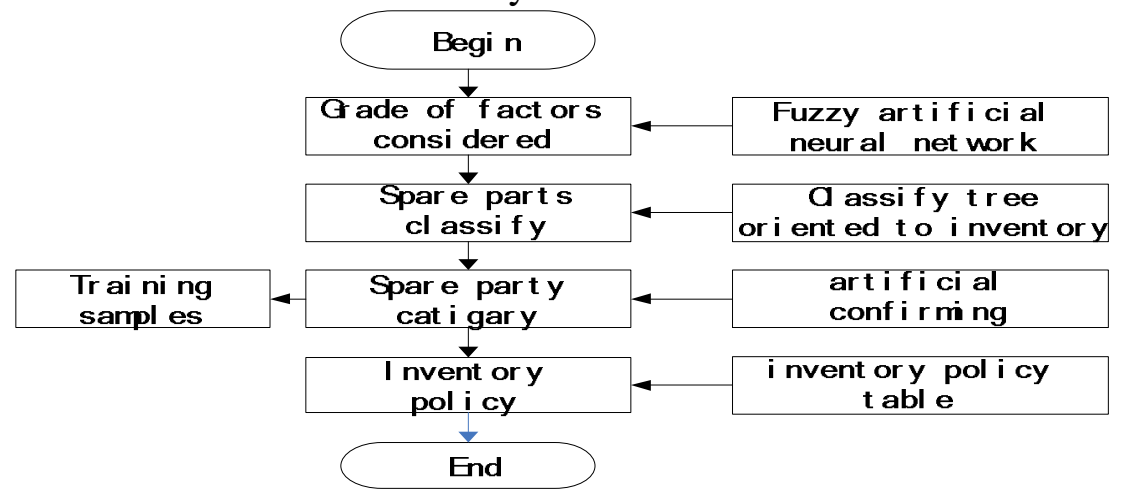

Fig.3. decision process of parts inventory tactic

\section{Acknowledgments}

This work is supported by the Project which is supported by National Science \& Technology Pillar Program in the Twelfth Five-Year Plan Period (2013BAF02B03).

\section{References}

[1] F.QIU, H.WANG, J.LI, Research and Development on Management Information System of the Multiple-sort \& Small-batch Materials in Lean Production, Journal of Wuhan University of Technology,vol.28(2009), p.117

[2] G. Neto, A. Gomes, J. Castro, et al. Integrating Activity Theory and Organizational Modeling for Context of Use Analysis, Proceedings of the 2005 Latin American conference on Human-computer interaction, CLIHC 2005, p.301

[3] T. Gruber, A Translation Approach to Portable Ontology Specification, In: Knowledge Acquisition, vol.5(1993),p.199

[4] Coulson, G. A Generic Component Model for Building Systems Software. ACM Transactions on 
Computer Systems, vol.26(2008),p.97

[5] G. Wagner. The Agent-object-relationship Meta-model: Towards a Unified View of State and Behavior, Information Systems, vol.28(2003), p.475 